\title{
Kitchen Waste Residues as Potential Renewable Biomass Resources for the Production of Multiple Fungal Carbohydrases and Second Generation Bioethanol
}

\author{
Chetna Janveja, Susheel Singh Rana and Sanjeev Kumar Soni*
}

\author{
Department of Microbiology, Panjab University, Chandigarh-160014, India
}

\begin{abstract}
Utilization of kitchen waste, the major portion of municipal solid waste for the coproduction of multiple carbohydrases and bioethanol was investigated in this study. Solid-state fermentation was performed to evaluate the potential of various steam pretreated kitchen waste residues as substrates for the coproduction of cellulolytic, hemicellulolytic, pectinolytic, amylolytic enzymes by a locally isolated strain of Aspergillus niger CJ-5. All the kitchen waste residues simply moistened with water, without the supplementation of exogenous nutrients proved good for the induction of all the enzyme components of a cocktail after $96 \mathrm{~h}$ incubation. Of all the substrates evaluated, steam pretreated potato peels induced maximum yields corresponding to $69.0 \pm 1.92 \mathrm{U}$ CMCase, $16.5 \pm 0.54 \mathrm{U}$ FPase, $44.0 \pm 1.28 \mathrm{U}$ $\beta$-glucosidase, 999.0 $\pm 28.90 \mathrm{U}$ xylanase, 58.2 $\pm 2.12 \mathrm{U}$ mannanase, $120.0 \pm 3.72 \mathrm{U}$ pectinase, $31520.0 \pm 375.78 \mathrm{U} \alpha$-amylase, $482.8 \pm 9.82 \mathrm{U}$ glucoamylase/g dry substrate (gds). Saccharification of residues using inhouse produced crude enzyme cocktail resulted in the release of $610 \pm 10.56,570 \pm 8.89,435 \pm 6.54,475 \pm 4.56,445 \pm 4.27,385 \pm 4.49,370 \pm 6.89,490 \pm 10.45$ $\mathrm{mg}$ of total reducing sugars $\mathrm{g}$ of dried potato peels, orange peels, pineapple peels, mausami peels, onion peels, banana stalks, pea pods and composite mixture respectively revealing carbohydrate conversion efficiencies in the range of 97.0$99.4 \%$. After fermentation of released hexoses, alcohol yields ranging from $80 \pm 1.069-262 \pm 7.86 \mu \mathrm{L} / \mathrm{gds}$ were obtained.
\end{abstract}

Keywords: Kitchen waste, Carbohydrases, Pretreatment, Enzymatic hydrolysis, Bioethanol.

\section{INTRODUCTION}

Energy and environmental issues are among the major concerns facing the global community today. In the twentieth century, major research emphasis was given for the development of petroleum, coal and natural gas based refinery to exploit the cheaply available fossil feed stock. These natural energy resources are being utilized at a rapid rate and not regarded sustainable. Moreover, these are questionable from the economic, ecological and environmental point of views due to their significant contribution to global warming [1]. Therefore, continuous efforts have to be emphasized towards the solution of the energy supply depletion problem and the environmental impacts caused by the human activities. Biofuels such as bioethanol, biodiesel and biohydrogen have been recognized as the potential alternatives to petroleum-derived transportation fuels as they can be utilized as such with little change to current technologies and have significant potential to improve sustainability. Ethanol production using sugary substrates (sugarcane juice, sugar cane molasses, beet molasses), starchy substrates (cereal grains like corn, wheat, rice, barley, sorghum, rye and root tubers like potato and cassava) is well known. However, many problems including food security and land substitution are brought up with the increasing demand for the first

\footnotetext{
*Address correspondence to this author at the Department of Microbiology, Panjab University, Chandigarh-160014, India; Tel: +91-172-2534149; Fax: +91-172-2541770; E-mail: sonisk@pu.ac.in
}

generation biofuels in transportation sector [2]. So, interest has now been dedicated to the utilization of alternative substrates that do not compete with the human food and whose availability is ensured in every corner of the world. Lignocellulosic biomass in the form of agricultural and municipal solid waste appears to be potential candidates for making the way forward in biofuels research and promise real emission savings over fossil fuel use [3]. Cellulose, hemicelluloses and lignin are the major components of lignocellulosic biomass with cellulose being the most abundant component comprising on an average 35 to $50 \%$ of biomass, whereas hemicelluloses and lignin comprise 20 to $35 \%$ and 5 to $30 \%$ of dry weight. The lignocellulosic materials investigated for bioethanol production at present are extensive and most of them come from land-derived resource: crop residues like agri-food wastes from fresh and processed vegetables [4], corn residue [5], herbages like water-hyacinth with high hemicelluloses [6], and silver grass for high xylose content [7]. Cellulases and hemicellulases are key resources in biorefineries, where they are used to produce alternative fuels and chemicals from lignocellulosic biomass.

Availability of feedstock and the cost of lignocellulolytic enzymes contribute to a large proportion of the total cost of bioethanol production. On-site production of enzymes by utilizing cheap and abundantly available substrates is one way of reducing the overall cost of bioethanol production. There is a 
wide spectrum of micro-organisms which can produce variety of enzymes like ligninases, cellulases, hemicellulases, pectinases, esterases, amylases, oxidoreductases and proteases under appropriate culture conditions [8]. Among the various bacteria and fungi capable of producing extracellular depolymerising enzymes, the latter have been found to be better in terms of the range of enzyme varieties and their yields, among them Trichoderma, Aspergillus, Penicillium and Fusarium genera are some of them [9, 10]. Cellulase production has been described for many Aspergillus species [11, 12]. Current cellulases have weak hemicellulase activity and are not sufficient for complete conversion to monomer sugars, so hemicellulases that can work synergistically with cellulases are required. Pectin, the cell wall component of plant material is composed of D-galacturonic acid which can be deconstructed by pectinolytic enzymes for decreasing the viscosity of medium and enhancing the effect of other hydrolytic enzymes. Amylases are also required to hydrolyze starchy component present in many peelings and brans.

The physicochemical and structural composition of native lignocellulosics in the waste residues is, however, recalcitrant to direct enzymatic hydrolysis of polysaccharides. For that purpose, various pretreatment processes are invariably required to render the polysaccharides amenable to enzymatic attack [13]. Enzymatic hydrolysis of pretreated biomass then requires synergistic action of a well-designed cocktail of enzymes [14]. Depolymerisation of cellulose requires the action of (i) endoglucanases (EC 3.2.1.4), which cleave internal $\beta$-1,4-glucosidic bonds (ii) exoglucanases (EC 3.2.1.91), which act on the reducing and non-reducing ends of cellulose chains to produce short-chain cellooligosaccharides (iii) $\beta$ glucosidases (EC 3.2.1.21), which hydrolyze soluble cello-oligosaccharides to fermentable glucose. As bulk of hemicellulose fraction is in the form of Xylan, its degradation process involves multiple enzymatic activities including xylanases (EC 3.2.1.8) which attack the internal $\beta-1,4$-xylosidic linkages of the xylan backbone giving rise to small oligoxyloside fragments which are acted upon by xylosidases (EC 3.2.1.37) thus completing the hydrolysis by releasing free sugars. Other hemicellulose components require the action of additional enzymes such as galactanase (EC 3.2.1.89), $\alpha$-glucuronidase (EC 3.2.1.139), $\beta$ mannanase (EC 3.2.1.78), $\beta$-mannosidase (EC 3.2.1.25). Pectin can be deconstructed by pectinases
(EC 3.2.1.15) while starch which forms a part of many peelings and brans, requires the synergistic action of $\alpha$ amylase (EC 3.2.1.1) and glucoamylase (EC 3.2.1.3) for its degradation.

Availability and cost of substrate account for a major fraction of the total cost of enzyme production and bioethanol generation. Research on the selection of suitable substrates have mainly been centered on agro-industrial and domestic waste residues due to their potential advantages for organisms, which are capable of penetrating into the hardest of these solid substrates, aided by the presence of turgor pressure at the tip of the mycelium [15]. These represent one of the most energy-rich resources on the planet, utilization of which has been in the frontier of industries practicing SSF to produce some valuable products and simultaneously reducing waste biomass going into landfills. Kitchen waste comprises more than half of the total fraction of municipal solid waste generated in the form of fruits and vegetable peelings. Current strategies for the management of this waste involve their disposal by land filling, thus contributing to global warming. Being a huge volume of urban waste, kitchen waste has the characteristic high moisture and organic component, which make it to be easily deteriorated and hard to handle. On the other hand, the abundant nutrition inside kitchen waste makes the waste an ideal raw material for the production of value added products, such as lactic acid, $\mathrm{CH}_{4}$, hydrogen and so on [16-18] so attention is being directed, now a days, to bio refinery processing of these waste to produce another valuable product such as ethanol. The utilization of kitchen waste residues as substrate for supporting fungal growth, enzyme(s) induction and ethanol production could help reduce the pollution threaten and bring down hydrolytic enzyme production cost and hence the enzymatic bioconversion of kitchen waste residues for ethanol production, thus it is worth investigating.

In view of this, attempts have been made in the present study to divert this zero cost abundant and otherwise unattended waste away from landfills by utilizing it as an alternative substrate for fungal growth and production of a cocktail of various hydrolytic enzymes. Further the efficacy of inhouse produced enzyme cocktail has been evaluated by carrying out the hydrolysis of various steam pretreated kitchen waste residues for the release of fermentable sugars and ethanol production. 


\section{MATERIALS AND METHODS}

\section{Screening and Isolation of Fungal Strain}

An extensive screening of fungal strains capable of producing appreciable levels of cellulolytic, hemicellulolytic, pectinolytic and amylolytic activity was done by collecting rotten food samples, decaying kitchen waste biomass from home and various places of Chandigarh city followed by their enrichment in the Yeast Nitrogen Base (YNB) supplemented separately with $2 \% \mathrm{w} / \mathrm{v}$ dried kitchen waste residues rich in cellulose, hemicellulose, pectin and starch. The flasks were incubated on a rotary shaker $(150 \mathrm{rpm})$ at $28^{\circ} \mathrm{C}$ for 4 days and those showing microbial growth were processed for the screening and isolation of desired strains by streaking the contents of enriched flasks on potato dextrose agar plates containing $0.5 \%$ of either of CMC, xylan, locust bean gum, pectin, soluble starch and incubating at $28^{\circ} \mathrm{C}$ for 4 days.

To visualize the hydrolysis zone in CMC and xylan supplemented media, the plates were flooded with an aqueous solution of $0.1 \%$ Congo red for $15 \mathrm{~min}$ and washed with $1 \mathrm{~N} \mathrm{NaCl} \mathrm{[19].} \mathrm{To} \mathrm{indicate} \mathrm{the} \mathrm{cellulase}$ and xylanase activities of the organism, diameters of clear zone around colony was measured in CMC and xylan containing plate respectively. The mannanase activity was evaluated by a clear zone around the colony in locust bean gum plates [20]. The clearing zone around the colony in pectin containing medium after addition of Logule's iodine solution was investigated and taken as criteria for determining the pectinolytic activity [21]. The degradation of starch was evaluated in the starch plate flooded with $0.2 \%$ iodine solution, where the cleared zone was seen around amylase producing colony under a blue background [22]. The degradation capabilities of various polysaccharides on agar plates were recorded as clear zone ratios (clear zone diameters/colony diameters). The selected fungal strain $\mathrm{CJ}-5$ was grown and maintained on potato dextrose agar plates at $28^{\circ} \mathrm{C}$ for 4 days to allow the development of spores and then stored at $4^{\circ} \mathrm{C}$ with periodic subculturing.

\section{Morphological and Molecular Analysis of the Fungal Strain}

The selected strain CJ-5 was cultivated on potato dextrose agar (PDA) plates at $28^{\circ} \mathrm{C}$ for $96 \mathrm{~h}$. The sporeproducing filamentous fungus was identified to the genus level based on morphological characteristics. Colony morphology of the fungus stained with lactophenol blue dye was examined with a light microscope. Complete identification of the strain was done with $18 \mathrm{~S}$ rDNA sequencing. For sequence analysis, DNA was extracted using a fungal genomic DNA isolation kit (RKT13; Chromous Biotech, India). The 18S rDNA sequences were amplified by PCR with primer pairs ITS1 (5'CTC GTA GGT GAA CCTTGC GG $3^{\prime}$ ) and ITS4 (5'GCC TCC GCT TAT TGA TAT GC $\left.3^{\prime}\right)$. The PCR products were stored at $4^{\circ} \mathrm{C}$, later analysed by $0.8 \%$ agarose gel electrophoresis, and then sequenced bi-directionally using the forward, reverse primers using $A B I 3130$ Genetic Analyzer by the services of Chromous Biotech, India. The sequence obtained was submitted to GenBank for homology with BLAST (http://ncbi.nim.nih.gov). The sequence data of 18S rDNA were aligned with those of the related fungal strains retrieved from the Genbank databases using MultAlign and analyzed to identify the fungal strain and its closest neighbors. A phylogenic tree was constructed from the evolutionary distance data by MEGA 4 software.

\section{Evaluation of the Fungal Strain for the Production of Multiple Carbohydrases in Solid State Fermentation}

After primary screening, evaluation of enzyme(s) production by the fungal isolate $\mathrm{CJ}-5$ was done by carrying out solid state fermentation in $250 \mathrm{ml}$ Erlenmeyer flasks, containing $5.0 \mathrm{~g}$ wheat bran moistened with distilled water to obtain a final substrate to moisture ratio of $1: 1.5$. The flasks were autoclaved, cooled and inoculated with five discs $(7 \mathrm{~mm})$ cut from the periphery of actively growing colonies on the PDA plates followed by their incubation at $28^{\circ} \mathrm{C}$ for $96 \mathrm{~h}$ under static conditions. The enzymes were extracted by adding $100 \mathrm{ml}$ of distilled water and $0.1 \%$ Tween 80 , shaking the flasks on a rotary shaker at $150 \mathrm{rpm}$ for 30-45 min at room temperature. The contents of the flask were then filtered through a metallic sieve and the solid residue pressed to release leftover liquid, centrifuged at $10,000 \mathrm{rpm}, 4^{\circ} \mathrm{C}$ for $10 \mathrm{~min}$ and the clear supernatant thus obtained was analyzed for various enzyme activities. The yields were expressed as $\mathrm{U} / \mathrm{g}$ dry substrate (gds).

\section{Enzyme Assays}

The supernatants obtained from solid state cultures were used as the extracellular enzyme preparations and assayed at $50^{\circ} \mathrm{C}, \mathrm{pH} 4.0$ for cellulases (exo- $\beta-1,4$ glucanase, endo- $\beta-1,4-$ glucanase, and $\beta-1,4-$ glucosidase), hemicellulases (xylanase, mannanase), pectinase and amylases ( $\alpha$-amylase, glucoamylase). 


\section{Cellulases}

Complete cellulase complex was measured in terms of endo- $\beta$-1,4-glucanase, exo- $\beta$-1,4-glucanase and $\beta$ glucosidase activities [23] and expressed in terms of CMCase, FPase and salicinase activities using CMC, Whatmann filter paper strips $(1 \times 6 \mathrm{~cm})$ and salicin respectively, as the substrates, and determining the $\mu$ moles of glucose liberated/min using dinitrosalicylic acid reagent [24].

\section{Hemicellulases}

Hemicellulases were determined in terms of endo$\beta-1,4-x y l a n a s e$ and endo- $\beta-1,4$-mannanase activities using xylan [25] and locust bean gum [26] respectively, as the substrates, and determining the $\mu$ moles of xylose and mannose liberated/min, respectively using dinitrosalicylic acid reagen [24].

\section{Pectinase}

This was estimated by using pectin as the substrate [27] and determining the $\mu$ moles of galactouronic acid liberated/min, using dinitrosalicylic acid reagent [24].

\section{Amylases}

These were determined in terms of $\alpha$-amylase and glucoamylase activities using soluble starch as the substrate and determining the hydrolysis of starch using iodine and the amount of glucose liberated, using dinitrosalicylic acid reagent [24] respectively. $\alpha$ amylase activity was expressed as equivalent to enzyme which reduces the colour of starch-iodine complex by $10 \%$ in 10 min [28] while glucoamylase activity was expressed in terms of $\mu$ moles of glucose liberated per min [29].

\section{Evaluation of Various Kitchen Waste Residues as Substrates for the Production of Multiple Carbohydrases by Solid State Fermentation}

Various kitchen waste residues including potato peels, orange peels, pineapple peels, mausami peels, onion peels, banana stalks, pea pods as well as composite mixture consisting of unseggregated residues were collected locally. These were dried by keeping them overnight in a hot air oven $\left(70^{\circ} \mathrm{C}\right)$, before being finely crushed in a laboratory grinder and finally stored in air tight containers until further use. All these residues, were subjected to solid state fermentation in $250 \mathrm{ml}$ Erlenmeyer flasks, separately, after steam treatment $\left(121^{\circ} \mathrm{C} ; 1 \mathrm{~h}\right)$ for evaluating the growth of fungal strain and production of all the enzyme components of the cocktail under solid state fermentation.

\section{Surface and Submerged State Fermentation}

The kitchen waste residue selected on the basis of enzyme yields under solid state fermentation was further analysed for enzyme productivities under surface and submerged state fermentation conditions. For this, $5 \mathrm{~g}$ of the steam treated composite mixture was taken as a basal medium for both surface and submerged culture fermentations in $250 \mathrm{ml}$ Erlenmeyer flasks containing $100 \mathrm{ml}$ distilled water. The media after sterilization was inoculated with five fungal discs $(7 \mathrm{~mm})$ cut from the periphery of actively growing culture and incubated at $28^{\circ} \mathrm{C}$ under static conditions for surface culture fermentation and on rotary shaker (150 rpm) for submerged state fermentation for 96h. Enzymes were extracted by directly centrifuging the contents of both the flasks. The supernatants thus obtained were analysed for the enzyme activities.

\section{Time Course for the Production of Multiple Carbohydrases in Solid State Fermentation}

The time course for the production of different components of a cocktail on composite residue was studied by preparing different sets of $250 \mathrm{ml}$ Erlenmeyer flasks, and carrying out the solid state fermentation for the period of ten consecutive days. For this, $5 \mathrm{~g}$ of the selected substrate was taken as a basal media, moistened with $7.5 \mathrm{ml}$ of distilled water. These were steam pretreated, cooled, inoculated and incubated at $28^{\circ} \mathrm{C}$ for a period of 10 consecutive days. The flasks were withdrawn at regular intervals of $24 \mathrm{~h}$ to study the production profiles of all the enzyme components of the cocktail.

\section{Evaluation of Various Kitchen Waste Residues as Substrates for Bioethanol Production by the Enzymes Produced in-House}

The efficacy of inhouse produced enzyme cocktail was evaluated by carrying out the hydrolysis of various kitchen waste residues and determining the amount of total reducing sugars and glucose released followed by fermentation with Saccharomyces cerevisiae. The total carbohydrate content of all the residues was analyzed by Anthrone method [30].

\section{Hydrolysis of Various Kitchen Waste Residues}

Ten grams of oven dried individual kitchen waste residues dispensed, separately, in $250 \mathrm{ml}$ Erlenmeyer 
flask containing $25 \mathrm{ml}$ distilled water were steam pretreated at $15 \mathrm{psi}$ for $30 \mathrm{~min}$. These was cooled and supplemented with crude enzyme cocktail from $A$. niger CJ-5 at enzyme to substrate ratio of $22 \mathrm{U}$ CMCase, $15 \mathrm{U}$ FPase, $10 \mathrm{U} \beta$-glucosidase, $260 \mathrm{U}$ xylanase, $54 \mathrm{U}$ mannanase, $69 \mathrm{U}$ pectinase, $4686 \mathrm{U} \alpha$ - amylase, $69 \mathrm{U}$ glucoamylase $/ \mathrm{g}$ substrate and $0.001 \%(\mathrm{w} / \mathrm{v})$ sodium azide to avoid bacterial contamination. Total volume in each flask was made to $50 \mathrm{ml}$ with $0.1 \mathrm{M}$ acetate buffer, $\mathrm{pH} 4$. The mixture was incubated at $50^{\circ} \mathrm{C}$ in a water bath shaker at $150 \mathrm{rpm}$ for $72 \mathrm{~h}$ and the samples were withdrawn at regular intervals of $24 \mathrm{~h}$, centrifuged at $10,000 \mathrm{rpm}$ for $10 \mathrm{~min}$ and supernatant analysed for total reducing sugars and glucose released by dinitrosalicylic acid (DNSA) and glucose oxidaseperoxidase method respectively [24, 31].

\section{Fermentation of Sugars}

The hydrolysates obtained after enzymatic hydrolysis of various kitchen waste residues were supplemented with $0.1 \%$ urea and $0.1 \% \mathrm{MgSO}_{4}$ then subjected to fermentation by inoculating with $10 \% \mathrm{v} / \mathrm{v}$ suspension of a distiller's strain of Saccharomyces cerevisiae in distilled water $\left(1.2 \times 10^{8} \mathrm{cells} / \mathrm{ml}\right)$, made from the overnight grown culture in MYGP broth (malt extarct, $0.3 \%$; yeast extract, $0.3 \%$; peptone, $0.5 \%$ and glucose, $1.0 \% \mathrm{w} / \mathrm{v})$. The flasks were kept at $25^{\circ} \mathrm{C}$ under stationary conditions for $72 \mathrm{~h}$ and the ethanol was measured using spectrophotometric method [32].

\section{Data Analysis}

All the values have been expressed as mean \pm standard deviation of three independent experiments with three replicates each. The results of enzymatic hydrolysis have been depicted in terms of carbohydrate conversion; total reducing sugars yield and glucose yield where as the results of fermentation have been expressed in terms of ethanol yield.

Carbohydrate conversion as percentage of the theoretical reducing sugars yield obtained from the equation which involves the transfer of carbohydrates to sugar $\left(\mathrm{C}_{6} \mathrm{H}_{10} \mathrm{O}_{5}\right)_{n}+{ }_{n} \mathrm{H}_{2} \mathrm{O} \rightarrow\left(\mathrm{C}_{6} \mathrm{H}_{12} \mathrm{O}_{6}\right)_{n}$ was computed by using the following formula:

Carbohydrate conversion $(\%)=[$ Reducing sugars] $/$ $(1.11 \times f \times[$ biomass $]) \times 100$

where [Reducing sugars] is the total reducing sugar concentration (g), [Biomass] is the concentration of dry Kitchen waste residue used in enzymatic hydrolysis; $f$ is the carbohydrate fraction (in terms of glucose) in dry biomass $(\mathrm{g} / \mathrm{g})$ and 1.11 is the factor that corresponds to the mass balance of the conversion of polysaccharides to sugars.

Reducing sugars and glucose yields have been expressed in terms of mass of total reducing sugars and glucose produced/mass of untreated kitchen waste residue. Alcohol yield has been expressed in terms of volume of alcohol produced/mass of untreated kitchen waste residues.

\section{RESULTS AND DISCUSSIONS}

In general, biomass to ethanol bioconversions involves the following steps: i) thermo-chemical pretreatment of the biomass, ii) production of a mixture of cellulolytic, hemicellulolytic, pectinolytic and amylolytic enzymes using a consortia of suitable microorganisms iii) bioconversion of pretreated biomass in to fermentable sugars and iv) microbial fermentation of sugars to ethanol. Among various bacteria and fungi capable of producing extracellular depolymerising enzymes, the latter have been found to be better in terms of the range of enzyme varieties and their yields as they can utilize a broader range of polysaccharides in comparison to bacteria. Therefore, interest in the search of fungal species capable of producing a mixture of biomass depolymerising enzymes including cellulases, hemicellulases, pectinases and amylases is increasing, so that an enzyme cocktail can be obtained for the complete hydrolysis of different polysaccharides of plant origin for the production of biofuels from lignocellulosic biomass [11].

\section{Screening and Isolation of Fungal Strain Capable of Coproducing Multiple Carbohydrases}

An extensive screening of natural habitats was carried out for the isolation of a fungal strain capable of coproducing appreciable levels of cellulolytic, hemicellulolytic, pectinolytic and amylolytic enzymes. Out of 100 fungal colonies isolated at $28^{\circ} \mathrm{C}, 10$ fungal colonies were selected on the basis of clearing zones on individual substrate containing potato agar plates including $0.5 \%$ of each of CMC, xylan, locust bean gum, pectin and starch. Of the various isolates evaluated, one fungal strain CJ-5 produced zone of clearance on all the carbohydrate containing plates with highest clear zone ratios and was thus selected for further studies (Table 1). 
Table 1: Various Fungal Isolates Selected on the Basis of Clear Zone Ratios

\begin{tabular}{|c|c|c|c|c|c|c|}
\hline \multirow{2}{*}{ Isolates } & \multirow{2}{*}{ Colony colour } & \multicolumn{5}{|c|}{ Clear zone ratios on various polysaccharides } \\
\cline { 3 - 6 } & & CMC & Xylan & Locust bean gum & Starch & - \\
\hline \hline CJ-1 & Green & 1.55 & 1.05 & 2.10 & 1.40 \\
\hline CJ-2 & Black & 2.0 & 1.90 & 1.00 & 2.05 \\
\hline CJ-3 & Dark green & - & 1.55 & 1.88 & - \\
\hline CJ-4 & Off white & - & 1.09 & - & 1.57 \\
\hline CJ-5 & Black & 2.15 & 2.00 & 1.50 & 3.07 & 1.92 \\
\hline CJ-6 & Yellowish brown & 1.55 & 1.17 & 1.48 & 1.45 \\
\hline CJ-7 & Dark green & - & 2.45 & - & - \\
\hline CJ-8 & Brownish black & - & 1.94 & 1.16 & - \\
\hline CJ-9 & White & 2.10 & - & - & - \\
\hline CJ-10 & Yellow & 1.25 & 2.15 & - & 1.90 \\
\hline
\end{tabular}

Morphological and Molecular Analysis of the Strain CJ-5

General morphological features for the identification of a fungal strain involve the screening of easily visible characteristics including conidial and mycelial colour, colony reverse colour, production of exudates and soluble pigments, presence of sclerotia and cleistothecia. Micromorphology characterization is mainly dependent on seriation, shape and size of vesicle, conidia and stipe morphology and morphology of cleistothecia and ascospores [33]. Strain CJ-5 was cultivated on a plate of potato dextrose agar (PDA) by incubating at $28^{\circ} \mathrm{C}$ for 4 days. The spore-producing filamentous fungus was identified to the genus level based on macroscopic and microscopic characteristics [34]. Colony morphology of the fungus was examined with a light microscope. Its growth was initially white, quickly becoming black with conidial spore production after $48 \mathrm{~h}$. Reverse of the colony was pale yellow and growth produced radial fissures in the agar. The microscopic analysis revealed it to be a strain of
Aspergillus. Complete identification of this strain was done with 18S rDNA sequencing taking the help of Chromus biotech, India. The sequence data obtained from 18S rDNA sequencing was aligned with those of the related fungal strains retrieved from the Genbank databases using MultAlign and analyzed to identify the fungal strain and its closest neighbours. A phylogenetic tree was constructed from the evolutionary distance data by MEGA 4 software. The $18 \mathrm{~S}$ rDNA of CJ-5 was successfully amplified by PCR with size of about 804 bp (Figure 1).

The aligned sequence of this amplified $804 \mathrm{bp} 18 \mathrm{~S}$ rDNA segment from CJ-5 was submitted to GenBank and after homology searching against the GenBank or the proprietary fungal DNA databases, the sequence of CJ-5 was found to share $99 \%$ similarity with those of Aspergillus niger (NCBI Acc No. >gil157837789). A phylogenetic relationship was established through the alignment and cladistic analysis of homologous nucleotide sequences among these fungal species. According to this phylogenetic analysis, strain $\mathrm{CJ}-5$

CGGAGGAAAANAAACCAACCGGGATTGCCTCAGTAACGGCGAGTGAAGCGGCAAGAGCTCAAATTTG AAAGCTGGCTCCTTCGGAGTCCGCATTGTAATTTGCAGAGGATGCTTTGGGTGCGGCCCCCGTCTAAGT GCCCTGGAACGGGCCGTCAGAGAGGGTGAGAATCCCGTCTTGGGCGGGGTGTCCGTGCCCGTGTAAA GCTCCTTCGACGAGTCGAGTTGTTTGGGAATGCAGCTCTAAATGGGTGGTAAATTTCATCTAAAGCTA AATACTGGCCGGAGACCGATAGCGCACAAGTAGAGTGATCGAAAGATGAAAAGCACTTTGAAAAGAG AGTTAAACAGCACGTGAAATTGTTGAAAGGGAAGCGCTTGCGACCAGACTCGCCCGCGGGGTTCAGC CGGCATTCGTGCCGGTGTACTTCCCCGTGGGCGGGCCAGCGTCGGTTTGGGCGGCCGGTCAAAGGCCC CTGGAATGTAGTACCCTCCGGGGTACCTTATAGCCAGGGGTGCAATGCGGCCAGCCTGGACCGAGGAA CGCGCTTCGGCACGGACGCTGGCATAATGGTCACCCGTCTTGAAACACGGACCAAGGAGTCTAACATC TACGCTCGACCGATCCTGATGTCTTCGGATGGATTTGAGTAAGAGCGTAAATGTGGGGACCCGAAAGA TGGTGAACTATGCCTGAATAGGGCGAAGCCAGAGGAAACTCTGGTGGAGGCTCGCAGCGGTTCTGAC GTGCAAATCGATCGTCAAATTTGGGTATAGGGGCGAAAGACTAATCGAACCATCTAGTAG

Figure 1: Aligned sequence data (804 bp) of $18 \mathrm{~S}$ rDNA amplified from fungal strain CJ-5. 
was identified as Aspergillus niger and was named as A. niger CJ-5.

\section{Production of Multiple Carbohydrases by Aspergillus niger CJ-5 in Solid State Fermentation}

The production of enzymes with SSF is gaining interest as a cost effective technology with an almost tenfold predicted reduction in costs and much higher yields as compared to submerged fermentation [35]. The nature of solid substrate is the most important factor in SSF for enzyme production as it not only supplies nutrients to the culture, but also serves as an anchorage for the microbial cells. Therefore, the particle size, chemical composition, cost and availability of the substrate are of critical importance during the selection of substrates. An ideal solid substrate should provide all the necessary nutrients to the growing microorganism for optimal function. However, some of the nutrients may be available in sub-optimal concentrations, or not even present in the substrate. In such cases, it would be necessary to supplement them externally. It has also been common practice to pretreat some substrates before use in SSF processes, making them more easily accessible for microbial growth [36]. Several agricultural crop residues, in the form of flours, brans, straws, hulls, residues of the fruit processing industries, waste of the oil processing mills have been successfully used in solid state fermentation. Wheat bran has been the prime among many solid state fermentation processes, which have been developed for the production of bulk chemicals and value added fine products [36]. The fungus $A$. niger $\mathrm{CJ}-5$ selected on the basis of clear zone ratios was then subjected to secondary screening to know the productivities of various hydrolytic enzymes by growing it as solid state cultures on wheat bran based solid media and then analyzing the enzyme yields. The selected fungal strain colonized well on wheat bran based basal media simply moistened with distilled water, without the addition of exogenous nutrients. The successful growth was probably due to the presence of adequate amounts of various nutrients, necessary for the cell mass formation as well as production of enzymes, such as proteins, amino acids, fats, carbohydrates including cellulose, hemicellulose, starch, pectin, ash, calcium and magnesium in wheat bran [11]. Enzyme productivities corresponding to 104.0 $\pm 3.25 \mathrm{U}$ of CMCase, $29.0 \pm 1.4 \mathrm{U}$ of FPase, $65.0 \pm 3.12 \mathrm{U}$ of $\beta$-glucosidase, $1444.0 \pm 40.45 \mathrm{U}$ of xylanase, $109.0 \pm 3.18 \mathrm{U}$ of mannanase, $95.0 \pm 3.64 \mathrm{U}$ of pectinase, $22556.0 \pm 451.28 \mathrm{U}$ of $\alpha$-amylase and $339.0 \pm 13.32 \mathrm{U}$ of glucoamylase /gds were obtained after $96 \mathrm{~h}$ growth. The production of a cocktail of hydrolytic enzymes by a single organism and that too in high titres imparts novely to the strain and makes it capable of being utilized for the hydrolysis of lignocellulosic residues rich in a variety of carbohydrates for ethanol production. Co-production of xylanolytic, pectinolytic, and cellulolytic enzymes has also been reported by Sporotricum thermophile in SSF with yields of $334.0,3.0$ and $7.7 \mathrm{U} / \mathrm{g}$ dry mouldy bran under unoptimized conditions [37].

\section{Evaluation of Various Pretreated Kitchen Waste Residues as Substrates for the Production of Multiple Carbohydrases by Aspergillus niger CJ-5}

The utilization of wheat bran as the substrate for fungal growth and enzyme production is not cost effective and is also debatable in terms of food and feed constraints. Hence, interest has now been dedicated to the utilization of waste residues that donot compete with the human food and feed demands. The use of abundantly available zero cost kitchen waste residues that are high in moisture content, rich in organic content, easily deteoriable and abundant in nutrition that were once considered to be of no value are presently being recognized as raw materials of potential value [38]. They have been utilized as substrates for the production of hydrogen, lactic acid and ethanol. Attempts have been made in the present study to utilize these waste residues including potato peels, orange peels, pineapple peels, mausami peels, onion peels, banana stalks, pea pods, composite mixture as raw materials under solid state fermentation for the production of a cocktail of various hydrolytic enzymes, that are a prerequisite for releasing sugars from the polysaccharides, thus reducing the cost of cellulases, hemicellulases, pectinases and amylases that are potentially an important class of enzymes from the industrial point of view. All the substrates simply moistened with distilled water, without any supplementation of exogenous nutrients proved to be well suited for organism growth and induction of all the components of enzyme cocktail.

Of all the substrates evaluated, potato peels gave the highest yields of all the enzyme components including CMCase $(69.0 \pm 1.92 \mathrm{U} / \mathrm{gds})$, FPase $(16.5 \pm 0.54 \mathrm{U} / \mathrm{gds}), \quad \beta$-glucosidase $(44.0 \pm 1.28 \mathrm{U} / \mathrm{gds})$, xylanase $(999.0 \pm 28.90 \mathrm{U} / \mathrm{gds}), \quad$ mannanase $(58.0 \pm 2.12 \mathrm{U} / \mathrm{gds})$, pectinase $(120.0 \pm 3.72 \mathrm{U} / \mathrm{gds})$, $\alpha$ amylase (31520.0 $\pm 375.78 \mathrm{U} / \mathrm{gds})$, glucoamylase $(482.8 \pm 9.82 \mathrm{U} / \mathrm{gds})$. Composite mixture proved to be the second best revealing comparable yields of all the 

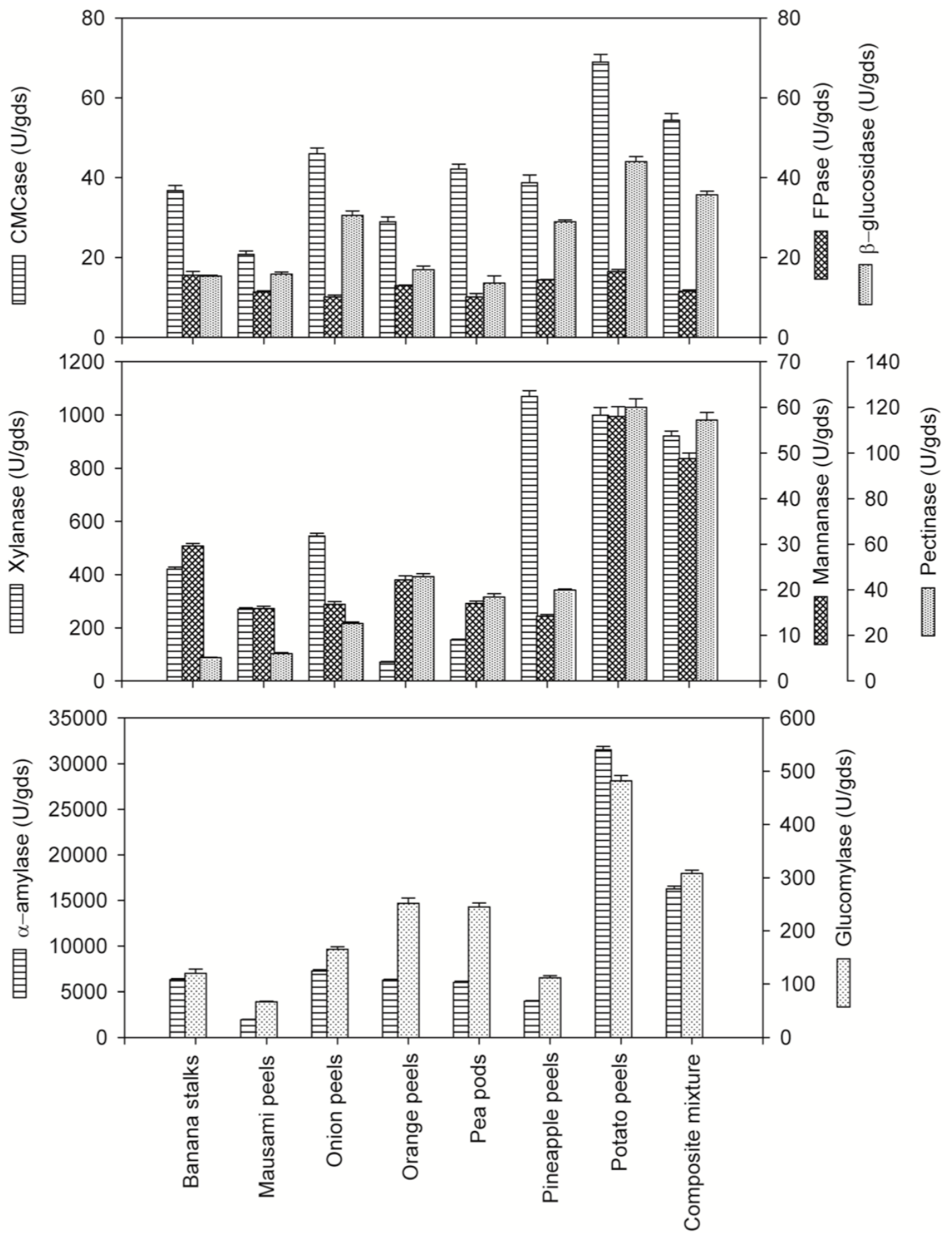

Figure 2: Enzyme yields obtained with various steam pretreated kitchen waste residues.

enzyme components corresponding to CMCase, $54.4 \pm 1.69 \mathrm{U} ; \quad F P a s e, 11.6 \pm 0.32 \mathrm{U} ; \quad \beta$-glucosidase, $35.8 \pm 0.87 \mathrm{U}$; xylanase, $920.8 \pm 18.54 \mathrm{U}$; mannanase, $48.8 \pm 1.19 \mathrm{U}$; pectinase, $114.4 \pm 3.36 \mathrm{U} ; \alpha$-amylase, $16259.0 \pm 325.32 \mathrm{U} ;$ glucoamylase, $308.0 \pm 6.36 \mathrm{U} / \mathrm{gds}$ (Figure 2). With steam pretreated substrates, the yields were quite high which might be due to disruption of lignin, hemicelluloses, reduction in cellulose, starch and pectin crystallinity thus making these more readily available for the microorganism. Chemical pretreatments of the lignocellulosic residues has also been studied by several workers for disintegration of lignin to enable the growth of the organism where in acid treatment causes degradation of hemicellulose, in addition to the formation of some inhibitory compounds including furfurals, and hydroxymethyl furfurals which along with lignin produce negative environment for an organism to grow, thus lowering the overall yields of enzymes produced [39]. Pretreating the substrates with sodium hydroxide causes easy removal of the lignin 
and hemicelluloses in addition to partial cellulose depolymerization by the separation of hydrogen bonds $[40,41]$ making these unavailable for the fungus leading to less growth and lower induction of enzyme components. Steam pretreatment used in the present study was found to be the optimum pretreatment strategy thus reducing the overall cost of substrate pretreatments by eliminating the expensive steps of chemical removal involved in acidic/basic pretreatments.

Many earlier studies have reported the production of cellulases, hemicellulases, pectinases and amylases from fungi in submerged as well as solid state fermentations, individually or in a mixture of few enzymes by supplementing expensive substrates including pure carbohydrates, nitrogen sources and a lot of minerals. The production of such a cocktail of various depolymerising enzymes by a single organism and that too in higher titres, as observed in the present study, on otherwise unattended highly deteoriable kitchen waste residues, simply moistened with distilled water without the supplementation of exogenous nutrients is worth appreciating. Very few reports have documented the preparation and characterization of inexpensive carbon sources for the production of lignocellulolytic enzymes. Doppelbauer et al. [42] used steam-treated wheat straw as the carbon source for the production of cellulases by $T$. reesei and only obtained 1.9 FPU/ $\mathrm{ml}$ of the product. Jorgensen and Olsson [1] reported low filter paper activity of $0.59 \mathrm{FPU} / \mathrm{ml}$, when a Penicillium brasilianum strain was used with steampretreated spruce as the carbon source. Cellulase productivity is lower when inexpensive carbon sources are used, such as pretreated lignocelluloses, rather than when commercial cellulose is used [1, 42]. In a study by Dhillon et al. [43] solid-state fermentation (SSF) was performed to evaluate the potential of agricultural residues for the production of cellulase and hemicellulase using individual and mixed cultures of Aspergillus niger and $T$. reseei. The maximum filter paper cellulase activity of $13.57 \mathrm{lU} / \mathrm{gds}, 22.89 \mathrm{IU} / \mathrm{gds}$ and $24.17 \mathrm{IU} / \mathrm{gds}$ and $\beta$-glucosidase activities of 21.69 $\mathrm{IU} / \mathrm{gds}, 13.58 \mathrm{IU} / \mathrm{gds}$ and $24.54 \mathrm{lU} / \mathrm{gds}$ were obtained with wheat bran medium at $96 \mathrm{~h}$ incubation period with A. niger, $T$. reseei and mixed cultures of $A$. niger and $T$. reseei, respectively.

\section{Production of Multiple Carbohydrases Under Solid, Submerged and Surface Culture Fermentation}

Of all the kitchen waste residues evaluated, potato peels and composite mixture proved to be better in terms of enzyme yields obtained. Out of the two, Composite mixture was selected for further experimentations, because of its relative abundance and easy availability. The ability of $A$. niger CJ-5 to produce multiple carbohydrases under different cultivation conditions was studied by growing on solid state medium, employing solid state fermentation (SSF) as well as liquid state medium employing surface culture fermentation (ScF) by cultivating under static conditions and submerged fermentation (SmF) by cultivating under shake conditions. Appreciable yields of all the enzyme components were obtained under solid state fermentation (SSF) conditions. Enzyme productivities were greatly reduced when the fungus was grown under liquid culture conditions. This might be due to low nutrient utilization or low surface area for the fungus to grow. Maximum productivities in solid state conditions might be due to large accessible area for the fungal mycelium to penetrate deep into the substrate as well as proper distribution of nutrients (Table 2).

The enzyme yields obtained in the present study are quite comparable to already published reports. This is probably the first study of this kind where a cocktail

Table 2: Production of Multiple Carbohydrases in Solid State, Submerged and Surface Culture Fermentations

\begin{tabular}{|c|c|c|c|}
\hline Enzymes & $\begin{array}{c}\text { Solid state fermentation } \\
\text { (U/gds) }\end{array}$ & $\begin{array}{c}\text { Submerged fermentation } \\
\text { (U/gds) }\end{array}$ & $\begin{array}{c}\text { Surface fermentation } \\
\text { (U/gds) }\end{array}$ \\
\hline \hline CMCase & $44.0 \pm 0.96$ & $19.2 \pm 0.32$ & $13.4 \pm 0.38$ \\
\hline FPase & $11.3 \pm 0.39$ & $11.8 \pm 0.26$ & $5.4 \pm 0.16$ \\
\hline$\beta$-glucosidase & $39.4 \pm 0.23$ & $25.2 \pm 0.32$ & $18.6 \pm 0.32$ \\
\hline Mannanase & $40.19 \pm 1.12$ & $23.4 \pm 0.26$ & $18.0 \pm 0.25$ \\
\hline Xylanase & $826.9 \pm 2.39$ & $119.6 \pm 0.96$ & $140.2 \pm 1.92$ \\
\hline Pectinase & $49.25 \pm 2.71$ & $44.6 \pm 0.35$ & $53.6 \pm 0.64$ \\
\hline Glucoamylase & $290.1 \pm 5.31$ & $19.4 \pm 0.09$ & $32.6 \pm 0.23$ \\
\hline$\alpha$-amylase & $1612.0 \pm 23.12$ & $1049.0 \pm 23.12$ & $896.0 \pm 9.32$ \\
\hline
\end{tabular}


of cellulolytic, hemicellulolytic, pectinolytic and amylolytic enzymes have been obtained on simple waste residues by a single fungal strain, without the incorporation of any expensive nutrient. Further the organism is able to colonize itself as solid as well as liquid state cultures, although the yields are comparatively less under liquid state cultures as compared to solid state fermentation. Production of a mixture of cellulases and xylanases by various fungal strains has also been reported earlier by several workers in submerged state fermentations employing highly enriched wheat barn, rice bran, straws and saw dust based media [44-46].

\section{Time Course for the Production of Multiple Carbohydrases in Solid State Fermentation}

The fungal strain of $A$. niger CJ-5 grown under SSF colonized well on simple composite mixture based solid substrate and exhibited good growth on surface,
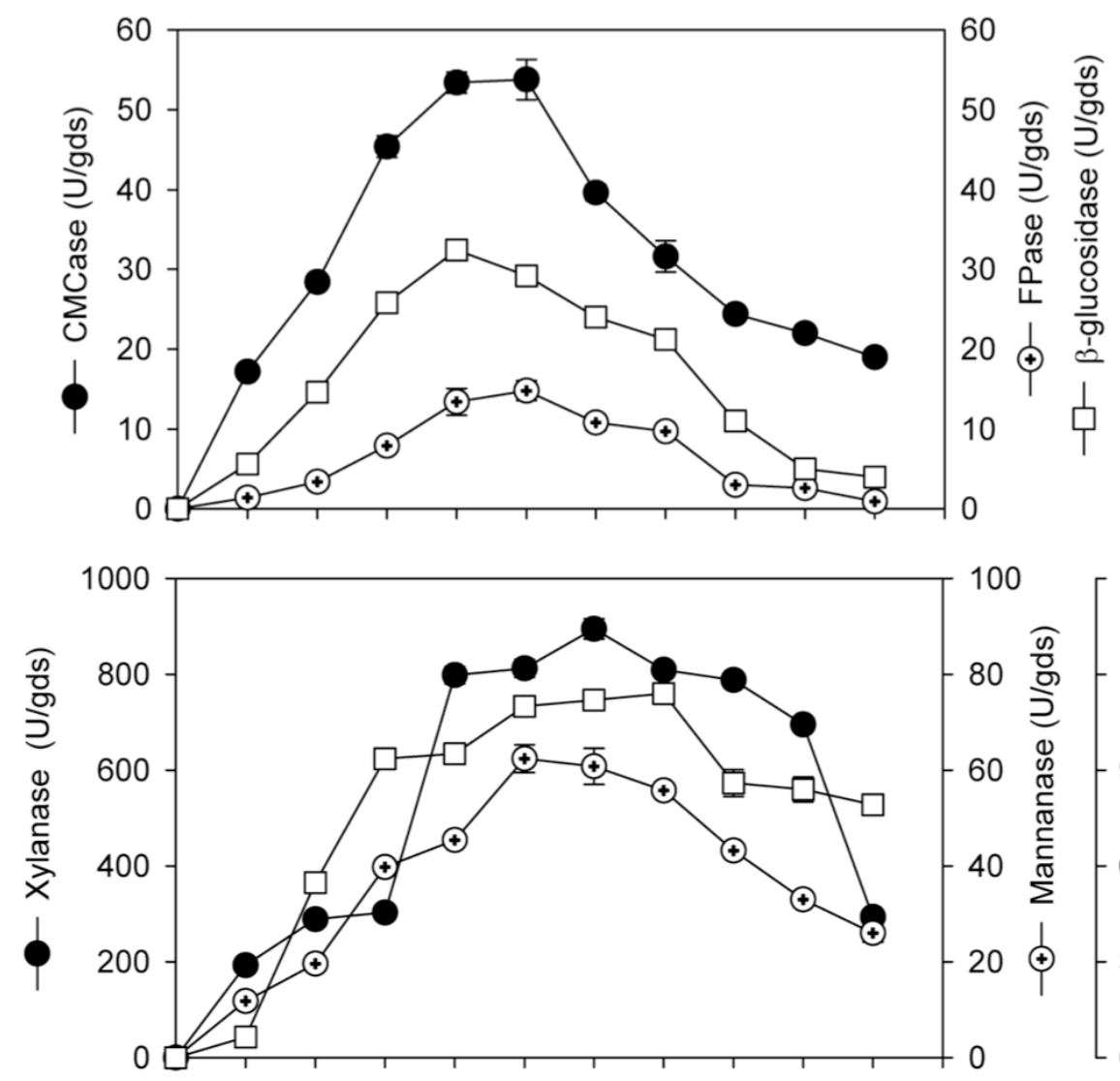

100
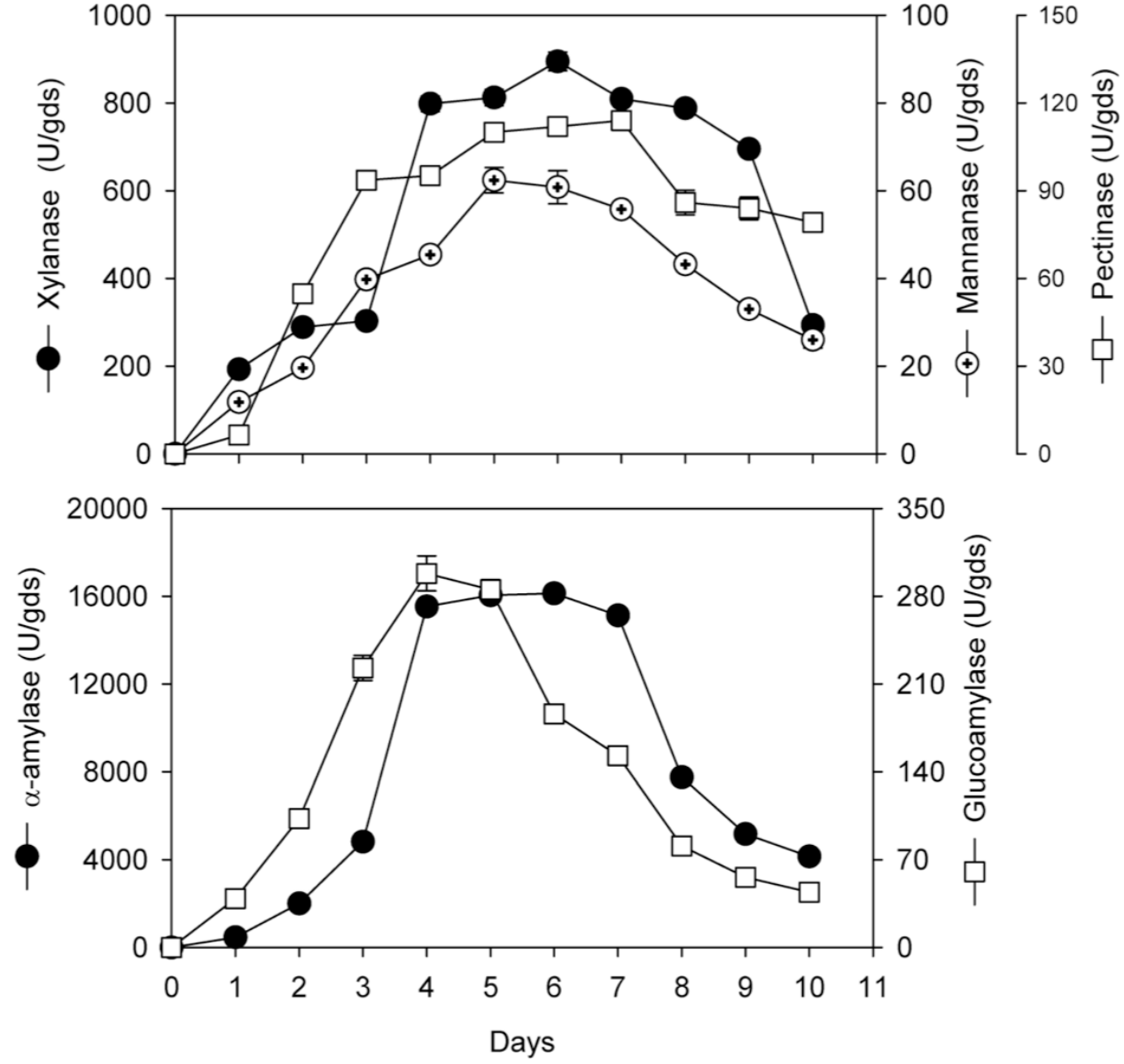

Figure 3: Time course of production of multiple carbohydrases including cellulases, hemicellulases, pectinase and amylases by Aspergillus niger CJ-5 under solid state fermentation. 
synthesizing all the enzyme components of a cocktail after 1 day of incubation. The growth and enzyme productivities improved gradually. CMCase, FPase, mannanase activities peaked up on $5^{\text {th }}$ day of incubation corresponding to $53.8 \pm 2.52 \mathrm{U}, 14.8 \pm 1.24 \mathrm{U}$, $62.4 \pm 2.89 \mathrm{U} / \mathrm{gds}$ respectively. Thereafter, there was a slight decrease in the enzyme activities. $\beta$-glucosidase production was found to be maximum on day 4 corresponding to $32.4 \pm 1.21 \mathrm{U} / \mathrm{gds}$. The productivity of xylanase showed up a continuous increase from day 2 , which peaked up to $895 \pm 21.09 \mathrm{U} / \mathrm{gds}$ on day 6 of incubation. Although enzyme activity was almost constant on day 6 , but revealed a gradual decrease thereafter. Similar trend was observed for pectinase production with the maximum production of $114.0 \pm 2.25 \mathrm{U} / \mathrm{gds}$ on seventh day. $\alpha$ - amylase production continued increasing upto sixth day yielding $16131.0 \pm 248.45 \mathrm{U} / \mathrm{gds}$ and showed a decline thereafter while glucoamylase production peaked up on fourth day yielding $298.2 \pm 13.87 \mathrm{U} / \mathrm{gds}$ (Figure 3 ). The decrease in the productivities with prolonged incubation period might be due to the release of proteases in the growth medium and/or due to the release of secondary metabolites during the stationary phase that might have inactivated the enzymes. To make a little compromise with the enzyme activities, day 5 was chosen to be optimal for maximum induction of all the components of enzyme system.

\section{Evaluation of Various Kitchen Waste Residues as Substrates for Bioethanol Production by the Carbohydrases Produced In-House}

The production of ethanol from any lignocellulosic biomass generally involves four steps- feedstock pretreatment, saccharification, fermentation and ethanol recovery. Hydrolysis can be carried out either by acids or by enzymes, but the latter is favoured as there is no formation of inhibitory compounds, that can interfere with the fermentation. Few lignocellulosic residues including sugarcane bagasse, wheat straw, corn stover, spruce and municipal solid waste residues have been worked upon by several workers for enzymatic bioconversion, with commercial or in-house produced cellulases, into fermentable sugars employing various pretreatment protocols including acid, alkali and steam [47]. After pretreatment, plant cell wall polysaccharides become more susceptible to enzymatic hydrolysis that results into monomeric sugars for fermentation into ethanol.

\section{Hydrolysis of Various Kitchen Waste Residues}

The efficacy of inhouse produced enzyme cocktail from $A$. niger $\mathrm{CJ}-5$, in hydrolyzing various kitchen waste residues was evaluated. Various kitchen waste residues, used in the present study on dry weight basis contained $38-62 \%$ carbohydrates (Table 3) consisting of various polysaccharides as evaluated by Anthrone method [30]. The enzyme preparation from A. niger CJ5 worked very well in the bioconversions of various carbohydrates present in steam-pretreated kitchen waste residues including potato peels, orange peels, mausami peels, pineapple peels, onion peels, banana stalks, pea pods and composite mixture. Maximum bioconversion was observed during the first $24 \mathrm{~h}$ of incubation and further incubation brought about slight gradual rise. Depending upon the type and effectiveness of pretreatment methods complete hydrolysis takes around 24-48h [48]. Highest yields of total reducing sugars and glucose were noted after 72 $\mathrm{h}$ reaction at $50^{\circ} \mathrm{C}$ in all the residues corresponding to $610.0 \pm 10.56, \quad 570.0 \pm 8.89,435.0 \pm 6.54,475.0 \pm 4.56$, $445.0 \pm 4.27,385.0 \pm 4.49,370.0 \pm 6.89,490.0 \pm 10.45$ and

Table 3: Total Carbohydrate Content and Alcohol Yields After the Enzymatic Hydrolysis of Various Kitchen Waste Residues by Multiple Carbohydrases from A. niger CJ-5

\begin{tabular}{|c|c|c|c|}
\hline Substrates & $\begin{array}{c}\text { Carbohydrate content } \\
(\%)\end{array}$ & $\begin{array}{c}\text { Carbohydrate conversion } \\
\text { efficiency (\%) }\end{array}$ & $\begin{array}{c}\text { Alcohol yield } \\
(\boldsymbol{\mu L} / \mathbf{g})\end{array}$ \\
\hline \hline Banana stalks & $39.2 \pm 1.17$ & 98.2 & $80 \pm 1.609$ \\
\hline Mausami peels & $48.6 \pm 0.478$ & 97.7 & $94 \pm 2.35$ \\
\hline Onion peels & $45.1 \pm 1.10$ & 98.6 & $100 \pm 2.89$ \\
\hline Orange peels & $57.3 \pm 1.14$ & 99.4 & $136 \pm 2.72$ \\
\hline Pea pods & $37.9 \pm 1.59$ & 97.6 & $80 \pm 2.46$ \\
\hline Pineapple peels & $44.1 \pm 2.25$ & 98.6 & $122 \pm 4.88$ \\
\hline Potato peels & $62.8 \pm 1.24$ & 97.0 & $262 \pm 7.86$ \\
\hline Composite mixture & $50.3 \pm 2.51$ & 97.4 & $153 \pm 5.45$ \\
\hline
\end{tabular}


$410.0 \pm 6.15, \quad 212.0 \pm 10.98, \quad 190.0 \pm 4.75, \quad 147.0 \pm 2.25$, $158.0 \pm 3.16,125.0 \pm 5.09,125.0 \pm 7.98,240.0 \pm 8.98 \mathrm{mg} / \mathrm{g}$ of dried potato peels, orange peels, pineapple peels, mausami peels, onion peels, banana stalks, pea pods and composite mixture respectively (Figure 4). Higher carbohydrate conversion efficiencies ranging from 97.0-99.4\% were achieved with crude enzyme cocktail. Total reducing sugars mainly comprised of glucose, mannose, galactose, xylose and arabinose, as detected by thin layer chromatography (data not shown) that can be fermented to alcohol by employing suitable yeast strains.

A few studies have reported the employment of consortia of fungal cultures or their enzyme preparations for saccharification of lignocellulosics for second generation ethanol production. Crude enzyme preparation from $P$. chrysogenum BCC4504 containing cellulase activity combined with $A$. flavus BCC7179 preparation containing complementary $\beta$-glucosidase activity were employed for the hydrolysis of cellulosic residues [49]. Saccharification of steam treated banana residues carried out with cellulases from Trichoderma lingorum resulted in the release of $1.34 \mathrm{mg} / \mathrm{ml}$ of reducing sugars at the end of $24 \mathrm{~h}$ [50]. Kovacs et al. [47] used three different steam-pretreated lignocellulosic substrates, namely spruce, wheat straw and sugarcane bagasse for enzymatic hydrolysis using commercial as well as laboratory produced enzymes and achieved the highest glucose yields of 29, 65 and $55 \%$ in case of spruce, wheat straw and sugarcane bagasse respectively.

In a similar study carried out by $\mathrm{Li}$ et al. [51] on selected municipal solid waste fractions, the highest glucose yield was obtained using potato peeling (89\%), followed by carrot peelings (73\%) or combination of carrot peelings and potato peelings (70\%). Newspaper

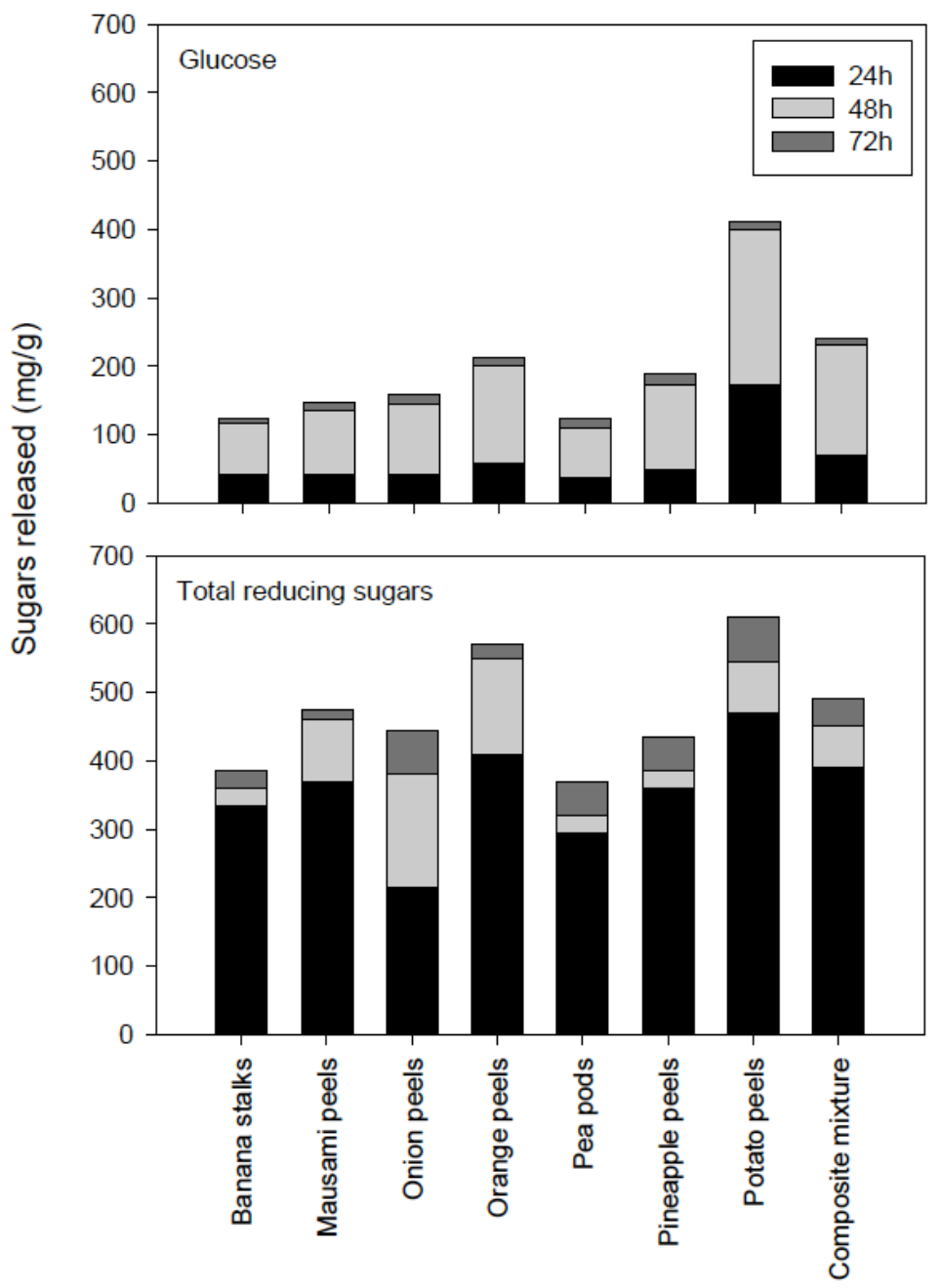

Substrates

Figure 4: Pattern of total reducing sugar and glucose yields during the enzymatic hydrolysis of various kitchen waste residues by multiple carbohydrases from $A$. niger CJ-5. 
produced the lowest glucose yield (14\%) after $96 \mathrm{~h}$ enzymatic hydrolysis with standard commercial cellulases from $T$. viride following pre-treatment with $4 \% \mathrm{H}_{2} \mathrm{SO}_{4}$ and steam. The glucose yield produced by a combination of five selected BMSW (biodegradable municipal solid waste) fractions was $52 \%$. The sugar yields obtained from few waste residues were also appreciable in comparison to most of the similar reports from other high cellulose agricultural residues like rice straw, wheat straw which revealed 157 and $214 \mathrm{mg}$ sugar $/ g$ of the residue respectively [52]. The utilization of inhouse produced enzyme cocktail in the hydrolysis of various carbohydrates present in different kitchen waste residues makes it a potential candidate for employment in the simultaneous saccharification of cellulose, xylan, mannan, pectin and starchy components of lignocellulosic biomass.

\section{Fermentation of Sugars}

The hydrolysates obtained after the enzymatic hydrolysis of various kitchen waste residues were subjected to fermentation by Saccharomyces cerevisiae. Appreciable alcohol yields equivalent to 80 $262 \mathrm{ml} / \mathrm{kg}$ of dried substrates were obtained in the present study. Maximium alcohol yields amounting to $262 \mu \mathrm{L} / \mathrm{g}$ of substrate were obtained with steam pretreated potato peels followed by composite mixture producing $153 \mu \mathrm{L} / \mathrm{g}$ (Table 3 ). The yields obtained with the steam pretreated kitchen waste residues are quite comparable to the already published reports utilizing various lignocellulosic residues. Few reports also exist on ethanol production from kitchen waste utilizing complex media composition as well as commercial enzymes for the hydrolysis.

An ethanol yield of $0.23 \mathrm{~g} / \mathrm{g}$ was obtained after $15 \mathrm{~h}$ of fermentation by $S$. cerevisiae by using the food waste broth hydrolyzed by the enzyme mixture [53]. In a study by Mukhopadhyay and Chatterjee [54], alcohol yields corresponding to $0.11 \mathrm{~g} / \mathrm{g}$ have been obtained from the enzymatic hydrolysis of acid-alkali pretreated water hyacinth. In another study, ethanol yield obtained from corncob was $0.48 \mathrm{~g} / \mathrm{g}$ [55] and from $P$. juliflora $(0.49 \mathrm{~g} / \mathrm{g})$ [56]. An ethanol yield of $0.109 \mathrm{~g} / \mathrm{g}$ of dry brewers spent grain was obtained with alkali pretreated BG under microaerobic conditions (0.01 vvm), corresponding to $60 \%$ of the theoretical yield based on total glucose and xylose content of BG [57]. Moreover, the alcohol obtained in the present study has been produced by targeting only hexoses by Saccharomyces cerevisiae while most of the published reports have simultaneously targeted both hexoses and pentoses using some other appropriate organisms or using a consortia of hexose and pentose fermenting orgaimsms. There is also a possibility of further raising the alcohol yield from the mixture of hexoses and pentoses produced in enzymatic hydrolysis using a consortia of appropriate microorganisms.

\section{CONCLUSIONS}

The present study has revealed various kitchen waste residues as valuable substrates for the coproduction of multiple carbohydrases and bioethanol generation. The ability of a single microbial strain belonging to Aspergillus niger $\mathrm{CJ}-5$ in the production of a cocktail of cellulose, hemicelluloses, pectin and starch degrading enzymes on various kitchen waste residues without any supplementation of exogenous nutrients imparts novelty to the work. Further the onsite produced enzyme cocktail was quite effective in hydrolyzing various steam-pretreated kitchen waste residues followed by alcohol production. Alcohol yields equivalent to $80-262 \mathrm{~L} /$ ton have been obtained from various dried kitchen waste residues after the fermentation of hexoses only and there is a possibility of further raising the ethanol productivities by fermenting pentoses with some other suitable microorganisms. The approach of utilizing zero cost kitchen waste residues as substrates for induction of a cocktail of hydrolytic enzymes and ethanol generation is expected to serve the objectives of management of otherwise highly deteoriable organic wastes causing environmental pollution problems, lower down the production cost of hydrolytic enzymes and developing a simple technique requiring no sophisticated instruments with practical applications. Further optimization of process parameters, simultaneous fermentation of C5 and C6 sugars using a consortia of suitable microorganisms and pilot scale studies need to be carried out in order to exploit these substrates for enzyme(s) production and second generation biofuel production.

\section{ACKNOWLEDGEMENTS}

The financial assistance provided by i) University Grants Commission (UGC), under SAP, ii) Department of Science and Technology (DST), Ministry of Science and Technology, Government of India under PURSE programme, iii) Indian Council of Medical Research (ICMR), in the form of a Junior Research Fellowship to Ms. Chetna Janveja and iv) Council of Scientific and Industrial Research (CSIR), in the form of Junior Research Fellowships to Mr. Susheel Singh Rana is highly acknowledged. 


\section{REFERENCES}

[1] Jorgensen $\mathrm{H}$, Olsson $\mathrm{L}$. Production of cellulase by Penicillium brasilianum IBT 20888: effect of substrate on hydrolytic performance. Enzyme Microb Technol 2006; 38: 381-90.

http://dx.doi.org/10.1016/i.enzmictec.2005.06.018

Leilei G, Peng W, Haijin M. Study on saccharification techniques of seaweed wastes for the transformation of ethanol. Renew Energ 2011; 36: 84-9.

http://dx.doi.org/10.1016/j.renene.2010.06.001

[3] Scharlemann JPW, Laurance WF. How green are biofuels? Environ Sci 2008; 319: 43-4.

[4] del Campo I, Alegría I, Zazpe M, Echeverría M, Echeverría I. Diluted acid hydrolysis pretreatment of agri-food wastes for bioethanol production. Ind Crop Prod 2006; 24: 214-21. http://dx.doi.org/10.1016/i.indcrop.2006.06.014

[5] Suurs RAA, Hekkert MP. Competition between first and second generation technologies: lessons from the formation of a biofuels innovation system in The Netherlands. Energ 2009; 34: 669-79. http://dx.doi.org/10.1016/i.energy.2008.09.002

Kumar A, Singh LK, Ghosh S. Bioconversion of lignocellulosic fraction of water hyacinth (Eichhornia crassipes) hemicellulose acid hydrolysate to ethanol by Pichia stipitis. Bioresour Technol 2009; 100: 3293-7. http://dx.doi.org/10.1016/j.biortech.2009.02.023

Guo GL, Chen WH, Chen WH, Men LC, Hwang WS. Characterization of dilute acid pretreatment of silver grass for ethanol production. Bioresour Technol 2008; 99: 6046-53. http://dx.doi.org/10.1016/j.biortech.2007.12.047

[8] Farinas CS, Loyo MM, Junior AB. Finding stable cellulase and xylanase: evaluation of the synergistic effect of $\mathrm{pH}$ and temperature. New Biotechnol 2010; 1: 1-6.

[9] Chandel AK, Singh OV, Chandrasekhar G, Rao LV, Narasu $M L$. Keydrivers influencing the commercialization of ethanol based biorefineries. J Comm Biotechnol 2010; 16: 239-57. http://dx.doi.org/10.1057/jcb.2010.5

[10] Sohail M, Naseeb S, Sherwani SK, Sultana S, Aftab S, Shahzad S, et al. Distribution of hydrolytic enzymes among native fungi: Aspergillus the predominant genus of hydrolase producer. Pak J Bot 2009; 41: 2567-82.

[11] Bansal N, Tewari R, Gupta JK, Soni SK, Soni R. A novel strain of Aspergillus niger producing a cocktail of industrial depolymerising enzymes for the production of second generation biofuels. BioRes 2011; 6: 552-69.

[12] Soni SK, Batra N, Bansal N, Soni R. Bioconversion of sugarcane bagasse into second generation bioethanol after enzymatic hydrolysis within house produced cellulases from Aspergillus sp. $\mathrm{S}_{4} \mathrm{~B}_{2} \mathrm{~F}$. BioRes 2010; 5: 741-58.

[13] Galbe M, Zacchi G. A review of the production of ethanol from softwood. Appl Microbiol Biotechnol 2009; 59: 618-28. http://dx.doi.org/10.1007/s00253-002-1058-9

[14] Bhat MK. Cellulases and related enymes in biotechnology. Biotechnol Adv 2000; 18: 355-83.

http://dx.doi.org/10.1016/S0734-9750(00)00041-0

[15] da Silva R, Lago ES, Merheb CW, Macchione MM, Park YK, Gomes E. Production of xylanase and CMCase on solid state fermentation in different residues by Thermoascus aurantiacus miehe. Braz J Microbiol 2005; 36: 235-41. http://dx.doi.org/10.1590/S1517-83822005000300006

[16] Han SK, Shin S. Biohydrogen production by anaerobic fermentation of food waste. Int J Hydrogen Energ 2004; 29: 569-77.

http://dx.doi.org/10.1016/j.ijhydene.2003.09.001

[17] Wang QH, Ymamabe $H$. Suppression of growth of putrefactive and food poisoning bacteria by lactic acid fermentation of kitchen waste. Process Biochem 2001; 37: 351-7.

http://dx.doi.org/10.1016/S0032-9592(01)00217-5

[18] Zhang B, Zhang LL, Zhang SC, Shi HZ, Cai WM. The influence of $\mathrm{pH}$ on hydrolysis and acidogenesis of kitchen wastes in two-phase anaerobic digestion. Environ Technol 2005; 26: 329-39.

http://dx.doi.org/10.1080/09593332608618563

[19] Teather RM, Wood PJ. Use of Congo red polysaccharide interaction in enumeration of cellulolytic bacteria from bovine rumen. Appl Environ Microbiol 1982; 43: 777-80.

[20] Phothichittol K, Nitisinprasert S, Keawsompong S. Isolation, screening and identification of mannanase producing microorganisms. Kasetsart J Nat Sci 2006; 40: 26-38.

[21] Reda AB, Hesham MY, Mahmoud AS, Ebtsam ZA. Production of bacterial pectinase(s) from agro-industrial wastes under solid state fermentation conditions. J Appl Sci Res 2008; 41: 1708-21.

[22] Bahadure RB, Agnihotri US, Akarte SR. Assay of population density of amylase producing bacteria from different soil samples contaminated with flowing effluents. Int $\mathrm{J}$ Parasitol Res 2010; 2: 9-13.

[23] Mandels M, Andreotti RE, Roche C. Measurements of saccharifying cellulases. Biotechnol Biophy Symp 1976; 6 : 21-3.

[24] Miller GL. Use of DNS reagent for determination of reducing sugars. Anal Chem 1959; 31: 426-8. http://dx.doi.org/10.1021/ac60147a030

[25] Bailey MJ, Biley P, Poutanen K. Inter laboratory testing of methods for assay of xylanase activity. J Biotechnol 1992; 23: $257-70$. http://dx.doi.org/10.1016/0168-1656(92)90074-J

[26] Stålbrand $\mathrm{H}$, Siika-aho $\mathrm{M}$, Viikari L. Purification and characterization of two $\beta$-mannanases from Trichoderma reesei. J Biotechnol 1993; 29: 229-42.

http://dx.doi.org/10.1016/0168-1656(93)90055-R

[27] Minjares-Carranco A, Trejo-Aguilar BA, Guillermo A, Viniegra-Gonzalez G. Physiological comparision between pectinase producing mutants of Aspergillus niger adopted either to solid state fermentation or submerged fermentation. Enzyme Microb Technol 1997; 21: 25-31. http://dx.doi.org/10.1016/S0141-0229(96)00212-8

[28] Fuwa H. A new method for micro determination of amylase activity by the use of amylose as substrate. J Biochem 1954; 41: 583-603.

[29] Cori GT. Amylo-1,6-glucosidase. Methods Enzymol 1955; 1: 211-4. http://dx.doi.org/10.1016/0076-6879(55)01029-X

[30] Updegroff DM. Semi micro determination of cellulose in biological materials. Anal Biochem 1969; 32: 420-4. http://dx.doi.org/10.1016/S0003-2697(69)80009-6

[31] Morin LG, Prox J. Single Glucose Oxidase-Peroxidase reagent for two-minute determination of serum glucose. Clin Chem 1973; 19: 959-62.

[32] Caputi A, Veda M, Brown T. Spectrophotometric determination of ethanol in wine. Am J Enol Vitic 1968; 19: 160-5.

[33] Geiser DM, Klich MA, Frisvad JC, Peterson SW, Varga J, Samson RA. The current status of species recognition and identification in Aspergillus. Stud Mycol 2007; 59: 1-10. http://dx.doi.org/10.3114/sim.2007.59.01

[34] Klich MA. Identification of common Aspergillus species. Ponsen \& Looijen, The Netherlands 2002.

[35] Singhania RR, Sukumaran RK, Pillai A, Prema $P$, Szakacs G, Pandey A. Solid-state fermentation of lignocellulosic substrates for cellulase production by Trichoderma reesei NRRL 11460. Indian J Biotechnol 2006; 5: 332-6. 
[36] Pandey A, Soccol CR, Rodriguez-Leon JA, Nigam P. Factors that influence on solid state fermentation, in: Pandey $A$, Ed. Solid state fermentation in Biotechnology: Fundamentals and Applications. Asiatech Publishers Inc., New Delhi 2001; pp. 21-9.

[37] Kaur G, Satyanarayana T. Production of extracellular pectinolytic, cellulolytic, xylanolytic enzyme by thermophilic mould Sporotrichum thermophile Apinis in solid state fermentation. Indian J Biotechnol 2004; 3: 552-7.

[38] Karmakar M, Ray R. Extra cellular endoglucanase production by Rhizopus oryzae in solid and liquid state fermentation of agro waste. Asian J Biotechnol 2010; 2: 27-50. http://dx.doi.org/10.3923/ajbkr.2010.27.36

[39] Hendriks ATWM, Zeeman G. Pretreatments to enhance the digestibility of lignocellulosic biomass. Bioresour Technol 2009; 100: 10-8.

http://dx.doi.org/10.1016/j.biortech.2008.05.027

[40] Damisa D, Ameh J, Umoh VJ. Effect of chemical pretreatment of some lignocellulosic wastes on the recovery of cellulase from Aspergillus niger $\mathrm{AH} 3$ mutant. Afr $\mathrm{J}$ Biotechnol 2008; 7: 2444-50.

[41] Alvira P, Tomas PE, Ballesteros M, Negro MJ. Pretreatment technologies for an efficient bioethanol production process based on enzymatic hydrolysis, A review. Bioresour Technol 2010; 101: 4851-61. http://dx.doi.org/10.1016/j.biortech.2009.11.093

[42] Doppelbauer $R$, Esterbauer $H$, Steiner W, Lafferty RM, Steinmuller $\mathrm{H}$. The use of lignocellulosic wastes for production of cellulase by Trichoderma reesei. Appl Microbiol Biotechnol 1987; 26: 485-94. http://dx.doi.org/10.1007/BF00253537

[43] Dhillon GS, Oberoi HS, Kaur S, Bansal S, Brar SK. Valueaddition of agricultural wastes for augmented cellulase and xylanase production through solid-state tray fermentation employing mixed-culture of fungi. Ind Crops Prod 2011; 34: 1160-7. http://dx.doi.org/10.1016/j.indcrop.2011.04.001

[44] Martín C, Marce M, Thomsen AB. Comparison of wet oxidation and steam explosion as pretreatment methods for bioethanol production from sugarcane bagasse. Biores 2008; 3: $670-83$.

[45] Ikram-ul-Haq, Javed MM, Khan TS. An innovative approach for hyper production of cellulolytic and hemicellulolytic enzymes by consortium of $A$. niger and $T$. viride MSK- 10 . Afr J Biotechnol 2006; 5: 609-14.

[46] Sridevi A, Narasimha G, Reddy BR. Production of cellulases by Aspergillus niger on natural and pretreated lignocellulosic waste. Int J Microbiol 2009; 7: 87-9.
[47] Kovacs K, Macrelli S, Szakacs G, Zacchi G. Enzymatic hydrolysis of steam-pretreated lignocellulosic materials with Trichoderma atroviride enzymes produced in-house. Biotechnol Biofuel 2009; 2: 5-14.

http://dx.doi.org/10.1186/1754-6834-2-14

[48] Lin Y, Tanaka S. Ethanol fermentation from biomass resources: current state and prospects. Appl Microbiol Biotechnol 2006; 69: 627-42. http://dx.doi.org/10.1007/s00253-005-0229-x

[49] Buaban B, Inoue H, Yano S, Tanapongpipat S, Ruanglek V, Champreda V, et al, Bioethanol production from ball milled bagasse using an on-site produced fungal enzyme cocktail and xylose-fermenting Pichia stipitis. J Biosci Bioeng 2010; 110: 18-25. http://dx.doi.org/10.1016/j.jbiosc.2009.12.003

[50] Baig MMV, Baig MLB, Baig MLA, Yasmeen M. Saccharification of banana agro-waste by cellulolytic enzymes. Afr J Biotechnol 2004; 3: 447-50.

[51] Li A, Antizar-Ladislao B, Khraisheh M. Bioconversion of municipal solid waste to glucose for bio-ethanol production. Bioprocess Biosyst Eng 2007; 30: 189-96.

http://dx.doi.org/10.1007/s00449-007-0114-3

[52] Deswal D, Khasa YP, Kuhad RC. Optimization of cellulase production by a brown rot fungus Fomitopsis sp. RCK2010 under solid state fermentation. BioRes 2011; 102: 6065-72. http://dx.doi.org/10.1016/j.biortech.2011.03.032

[53] Moon HC, Song S, Kim JC, Shirai Y, Lee DH, Kim JK, et al. Enzymatic hydrolysis of food waste and ethanol fermentation. Int J Energy Res 2009; 33: 164-72. http://dx.doi.org/10.1002/er.1432

[54] Mukhopadhyay S, Chaterjee NC. Bioconversion of water hyacinth hydrolysate into ethanol. Biores 2010; 5: 1301-10.

[55] Chen M, Xia L, Xue P. Enzymatic hydrolysis of corncob and ethanol production from cellulosic hydrolysate. Int Biodeter Biodegr 2007; 59: 85-9. http://dx.doi.org/10.1016/j.ibiod.2006.07.011

[56] Gupta R, Sharma KK, Kuhad RC. Separate hydrolysis and fermentation (SHF) of Prosopis juliflora, woody substrate for the production of cellulosic ethanol by Saccharomyces cerevisiae and Pichia stipitis NCIM 3498. Bioresour Technol 2009; 100: 1214-20.

http://dx.doi.org/10.1016/j.biortech.2008.08.033

[57] Xiros C, Christakopoulos P. Enhanced ethanol production from brewer's spent grain by a Fusarium oxysporum consolidated system. Biotechnol Biofuel 2009; 2: 1-12. http://dx.doi.org/10.1186/1754-6834-2-4 